\title{
MARGINAL ADAPTATION OF A NEW FORMULATION OF MTA MATERIAL USED AS ROOT-END FILLING: A SCANNING ELECTRON MICROSCOPY (SEM) STUDY
}

\author{
Samia M El-Sherief *, Mohamed Ibrahim Rabie** and Ahmed M Negm***
}

\begin{abstract}
Introduction Achieving a hermetic apical seal is mandatory to prevent ingress of any microorganisms or periapical fluids into the root canal system. Therefore it is essential to develop new materials having favorable physical, chemical and biological properties.
\end{abstract}

Aim the purpose of this study was to use scanning electron microscopy to compare the marginal adaptation of new formulation of MTA (Harvard MTA), MTA flow and glass ionomer as root end filling materials using ultrasonic root-end preparation.

Methodology Thirty-nine extracted single rooted human teeth were prepared using Protaper Next file system (Dentsply/Sirona) and filled with gutta-percha and MTA fillapex sealer (MTA Fillapex; Angelus, Londrina, Brazil) and obturated using cold lateral compaction technique. The apical $3 \mathrm{~mm}$ of the roots were sectioned perpendicular to the long axis of the roots. A 3-mm depth root-end cavity was prepared with ultrasonic tips powered by an Enac ultrasonic device. The teeth were randomly allocated into three groups of 13 teeth each according to filling materials tested. Group I the samples were filled with Harvard MTA (Universal, Handmix, Germany, Harvard), Group II filled with MTA Flow (Ultradent Products Inc., South Jordan,UT, USA), group III filled with glass ionomer (Fuji II, GC gold label 2, GC International, Japan). Using SEM the distance between the tested materials and the surrounding dentin was measured at different points.

Results According to the results of Kruskal-Wallis, there was significant difference between the three experimental groups at P value 0.01 . The Man Whitney test was used for two-by-two comparison of the groups which revealed no statistical significant difference between MTA flow and MTA Harvard group however; there was statistically significant difference in Glass Ionomer group.

Conclusion SEM results showed the presence of gaps in the root-end filling materials in all groups. MTA flow has the best marginal adaptation followed by MTA Harvard while the Glass Ionomer showed the least marginal adaptation.

Keywords: Root-end filling materials, Mineral trioxide aggregate, Glass Ionomer, Marginal adaptation, SEM.

\footnotetext{
* Associate Professor of Endodontics, Faculty of Oral and Dental Medicine, Cairo University

** Lecturer of Endodontics, College of Dentistry, Suez Canal University.

*** Lecturer Ahram Candian University
} 


\section{INTRODUCTION}

Periapical surgery may be an alternative option of treatment if conventional root canal retreatment is failed. In these cases surgery is considered a better choice as it saves the tooth rather than extraction. ${ }^{(1)}$

Periapical surgical steps includes surgical debridement of pathological lesion, root-end resection, root-end cavity preparation with sonic or ultrasonic surgical retrotips that have been used to improve the accessibility, alignment and cavity depth, and filling with a biocompatible root-end filling material to seal the root canal portals ${ }^{(2,3)}$.

The presence of microorganisms in root canal system can initiate periapical lesions ${ }^{(4)}$. The marginal adaptation is related to sealing ability, so it is responsible for the long-term clinical success ${ }^{(5,6)}$.

Retrograde filling following root end cavity preparation is an important step in periapical surgery, aimed at tight three-dimensional hermetic sealing against the leakage of irritants from the root canal to the periapical area. Incomplete seal of retrograde cavity is considered the main cause of treatment failure ${ }^{(7)}$. Thus continuous development of new materials aiming to improve physical, chemical and biological properties of filling materials is mandatory.

Glass ionomer cement (GICs) had been recommended as root-end fillings due to its low toxicity; GICs also this cement doesn't induce inflammatory reactions and is a biocompatible material. ${ }^{\left({ }^{89}\right)}$. Several studies have reported that these cements decrease microleakage as they have the ability to form chemical bond to the tooth and have proper sealing ability ${ }^{(10)}$.

Tricalcium silicate based materials, as mineral trioxide aggregate (MTA), have appropriate biological, physicochemical and mechanical characteristics that are suitable for many different clinical applications. Several studies evaluated the MTA as a root-end filling material ${ }^{(11,12)}$. A drawback of some MTA-based materials, such is their difficult handling properties renders them challenging of clinical use ${ }^{(13)}$.

MTA Flow (Ultradent Products Inc., South Jordan, UT, and USA) consists of a gray powder of dicalcium and tricalcium silicate, bismuth oxide and a liquid water-soluble gel. It was introduced to overcome the shortcomings of MTA. It is a calcium silicate based material that has a smaller particle size and more pure composition than the conventional MTA. It is available in a powder and a gel. The powder's particle size is less than $10 \mu \mathrm{m}$. It has the same physical properties as conventional MTA mixing resulting in a smooth consistency that is easy to be inserted into the indicated site ${ }^{(14)}$. MTA Flow has a short setting time up to 15 minutes. Mixing the powder and liquid produces less sandy mixture that is easier to be handled. MTA Flow ${ }^{\mathrm{TM}}$ requires a moist environment to enhance the setting process effectively, so it not affected by blood or fluid. More recently it was concluded that MTA Flow stimulates bio-mineralization ${ }^{(15)}$. MTA Flow is alkaline $\mathrm{pH}$, low solubility, and acceptable radio-opacity and was able to form calcium and phosphate deposits ${ }^{(16)}$.

New formulation of MTA materials is now available in the dental market such as Harvard MTA. (Universal, Germany, Harvard) It is biocompatible material presented as powder and liquid in two forms capsules and hand mix, with many clinical indications as pulp capping and pulpotomy as it can form tertiary dentin for dentin bridge formation, root end fillings both orthograde or retrograde and as a perforation repair.

The outcome of root canal treatment is decreased by failure in marginal adaptation of the filing material, and gaps at the interface between the filling and the dentin walls. There are almost no studies about Harvard MTA so this study was conducted to compare the marginal adaptation of three root end filling materials namely; Harvard MTA Universal Hand Mix, MTA Flow and Glass Ionomer; the marginal adaptation was evaluated using scanning electron microscopy (SEM). 


\section{MATERIALS AND METHODS}

\section{Specimen selection}

Thirty-nine single-rooted teeth were selected with inclusion criteria; absence of root canal calcifications, crack lines or fracture, internal or external resorption, previous root filling and the presence of mature root with a fully formed apex.

The teeth were stored on $0.2 \%$ thymol solution, and then immersed in 5\% sodium hypochlorite for $30 \mathrm{~min}$ to remove soft tissues.

\section{Specimen Preparation}

The working length of the canals was measured using K-Files (Dentsply Maillefer, Ballaigues, Switzerland) to be $1 \mathrm{~mm}$ short of the apical foramen. Glide path was achieved with hand instruments and the preparation was completed using Protaper Next (Dentsply Sirona). During instrumentation, glyde was used as lubricant, the root canals were irrigated with $3 \mathrm{~mL}$ of $1 \% \mathrm{NaOCl}$ after each files and $17 \%$ EDTA (Biodinâmica, Ibiporã, PR, Brazil) for 3 min to remove the smear layer. Finally, the root canals were irrigated with $3 \mathrm{~mL}$ of $1 \% \mathrm{NaOCl}$ and dried with paper points (Dentsply Maillefer, Ballaigues, Switzerland).

The root canals were obturated with gutta percha designed for Protaper Next (Dentsply Sirona) and MTA Fillapex sealer (MTA Fillapex; Angelus, Londrina, Brazil) using lateral compaction technique.

The apical $3 \mathrm{~mm}$ of roots was sectioned in perpendicular direction to the long axis of the root using a high-speed diamond disc under continuous water spray. A 3-mm-depth root-end cavity will be prepared with DF. 908 ultrasonic tips (Osada Eletric, CO., Osada, Japan) powered by an Enac ultrasonic unit (Osada Eletric CO., Osada, Japan) under continuous irrigation with saline solution.

The teeth were randomly allocated into three groups, according to the materials used.

Group I: Harvard MTA (Universal, Handmix, Germany, Harvard)
Group II: MTA Flow (Ultradent Products, Inc.)

Group III: GIC (Fuji II, GC gold label 2, GC International, Japan).

The materials were mixed according to the manufacturers' instruction, and then the root-end cavities were filled. The samples were wrapped with wet gauze and stored in an incubator at $37^{\circ} \mathrm{C}$ for 24 $\mathrm{h}$ to allow complete setting of the tested materials.

One mm transverse section from the apex of the root ends was sectioned with a slow-speed diamond disc.

\section{Evaluation of Marginal Adaptation}

The specimen sections were placed in a vials containing $2.25 \%$ sodium hypochlorite solution for $3 \mathrm{~h}$. The specimens were dehydrated for $5 \mathrm{~h}$ in increasing concentrations of alcohol 70, 90 and $99 \%$, and then the specimens were fixed on metal stubs, and sputter coated with $150-\AA$ thick gold palladium. Analysis of the samples using SEM (model JEOL 6490LV SEM, JEOL USA) was done by two observers independently to evaluate presence of marginal gaps at the dentin-material interface in each specimen.

\section{Statistical analysis}

The data of different types of root-end filling materials were analyzed using SPSS 22.0 software. The marginal gap of the materials in each group was compared using the Kruskal-Wallis test with $\mathrm{P}<0.01$ level of significance and Man Whitney test, was used for two-by-two comparison of the groups.

\section{RESULTS}

According to the results of Kruskal-Wallis tests table (1) fig (1), there was significant difference between the three experimental groups at $\mathrm{P}$ value 0.01 . Man Whitney test was used for two-by-two comparison of the groups demonstrated no statistically significant difference between MTA Flow, Harvard MTA while there was significant difference in Glass Ionomer group. The marginal adaptation in MTA Flow was better than other two groups. 
TABLE (1) Means and standard deviation of MTA Flow, Harvard MTA and Glass Ionomer groups.

\begin{tabular}{|l|c|c|c|c|}
\hline Groups & Min & Max & Mean \pm SD & P-value \\
\hline MTA flow & 1.91 & 6.78 & $3.95 \pm 1.47^{\mathrm{c}}$ & \\
\cline { 1 - 4 } Harvard MTA & 4.98 & 11.34 & $7.44 \pm 1.83^{\mathrm{b}}$ & \multirow{2}{*}{$0.000^{* *}$} \\
\cline { 1 - 4 } Glass Ionomer & 8.9 & 18.49 & $12.59 \pm 2.57^{\mathrm{a}}$ & \\
\hline
\end{tabular}

** indicate significant difference at $1 \%$ probability level,

$a, b, c ;$ Means with different letter at the same columns are statistically significant at $1 \%$ level probability

The results obtained by the SEM of the samples

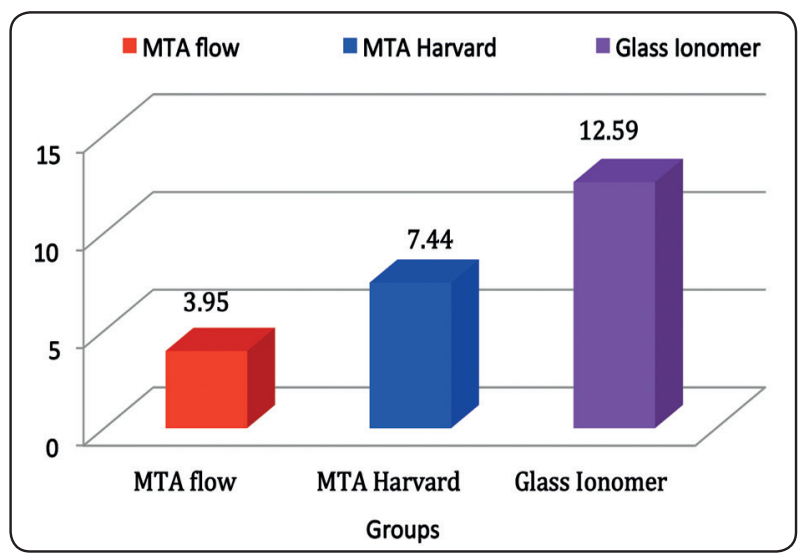

Fig (1) Bar diagram representing the mean value of MTA flow, Harvard MTA and Glass Ionomer groups.
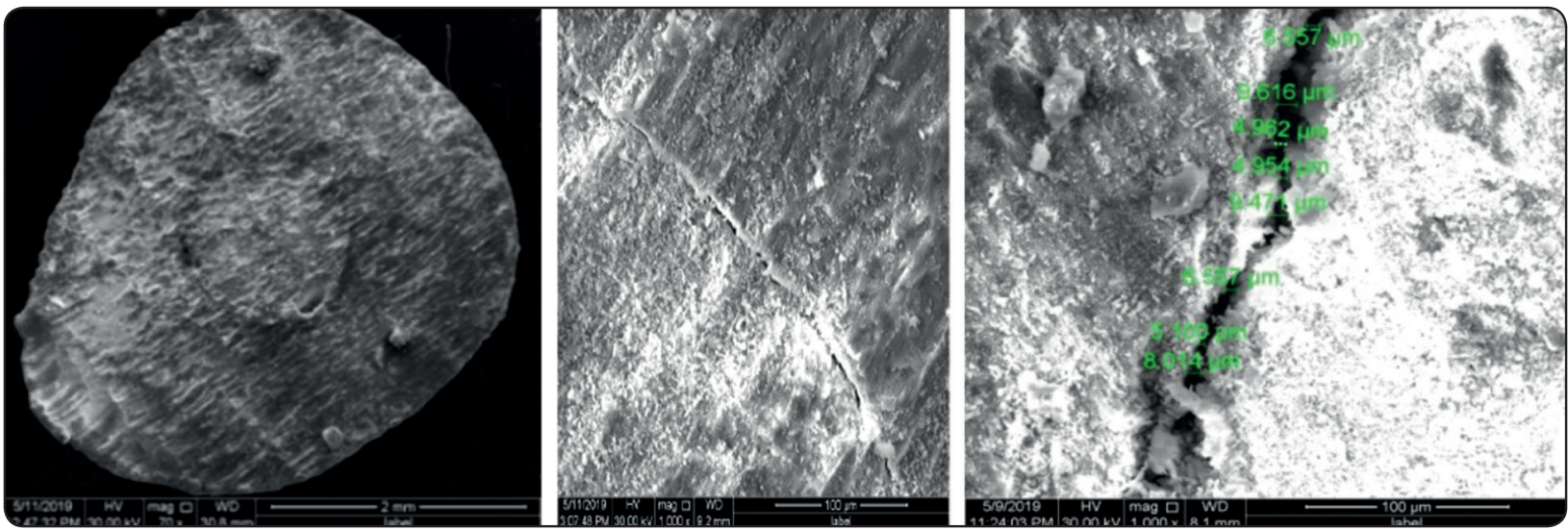

Fig (2) Scanning electron Photomicrograph of Harvard MTA root-end filling material.
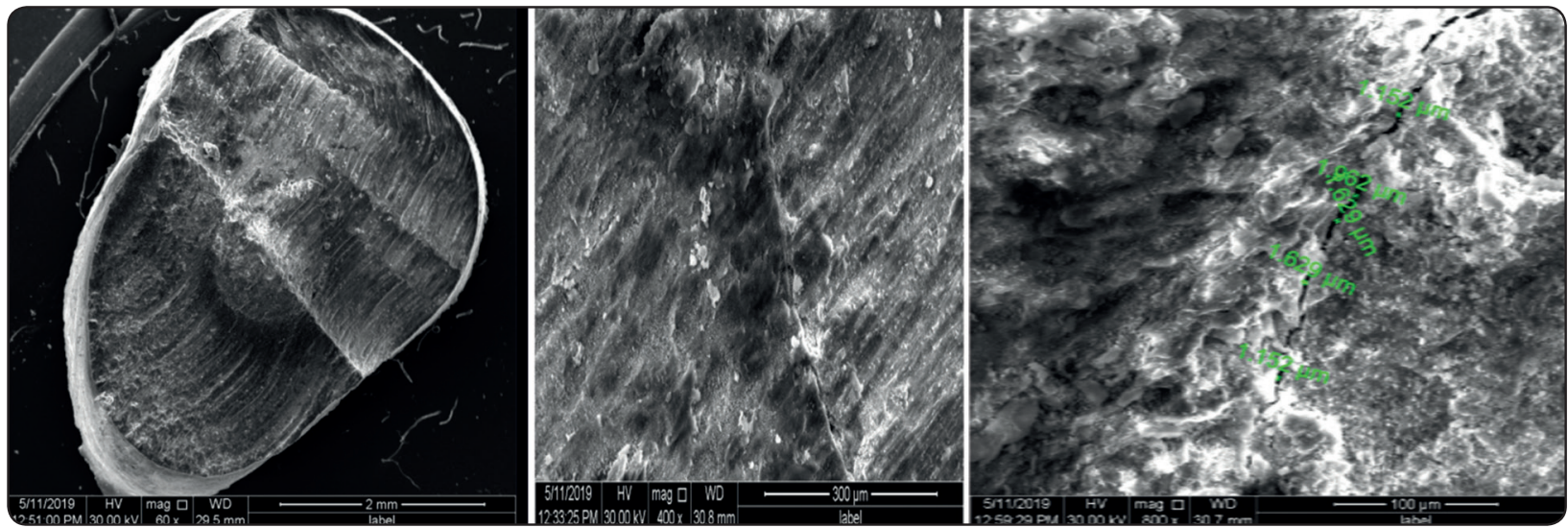

Fig (3) Scanning electron Photomicrograph of MTA Flow root-end filling material. 


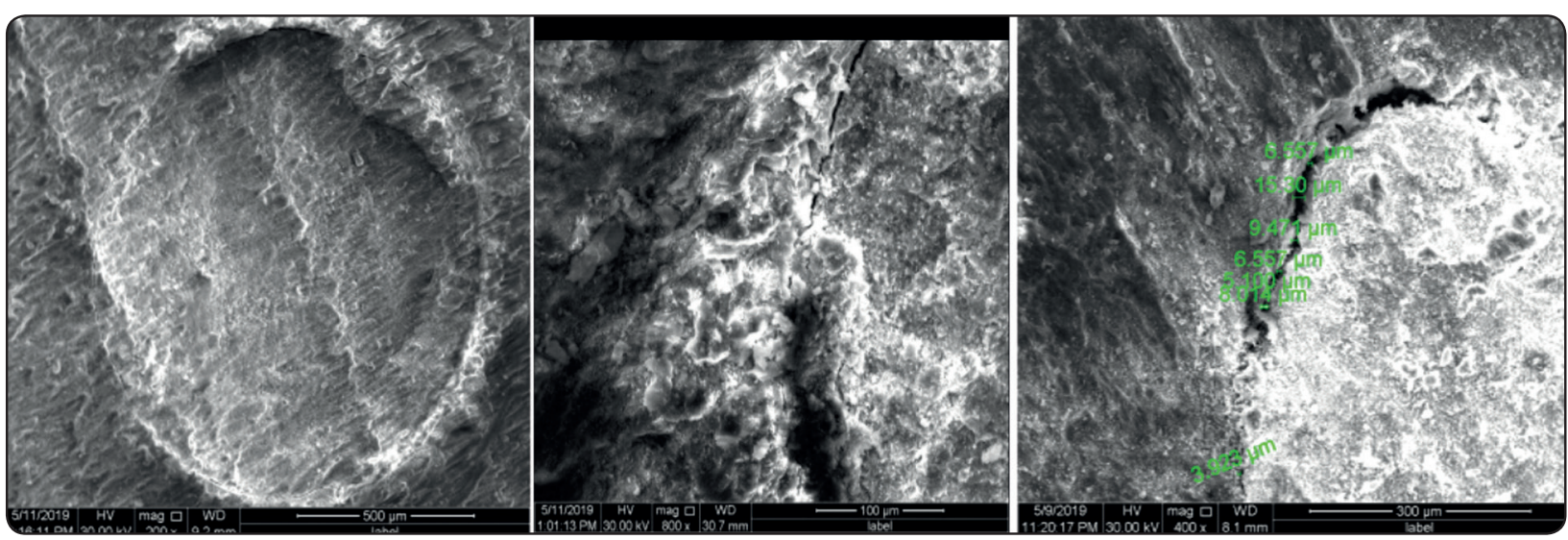

Fig (4) Scanning electron Photomicrograph of Glass Ionomer root-end filling material.

\section{DISCUSSION}

The success of root canal treatment whether conventional or surgical treatment depends mainly on coronal and apical sealing. So preventing microleakage was the interest of many studies that evaluated the marginal adaptation of different root-end filling materials with biocompatible properties. ${ }^{(17-19)}$

The aim of periradicular surgery is to achieve access to the root canal that is difficult to be cleaned from orthograde access, evaluation of root anatomy and inoculation of pathological lesion ${ }^{(1-3)}$.

Scanning electron microscopy (SEM) has been used to assess the marginal adaptation of filling materials ${ }^{(19,20)}$.

Several studies showed that the clinical success of MTA based on its proper apical sealing, and its excellent biocompatibility in comparison to

other root end filling materials. MTA has powder of hydrophilic particles that allows setting in the presence of moisture, specifically blood that is often causing a problem with other materials which are used in apical surgery ${ }^{(21-23)}$.

Scanning electron microscopy (SEM) with its high magnifications has been used to measure the gaps at the interface between dentin and rootend filling material and to analyze the marginal adaptation ${ }^{(24,25)}$.
Our results showed that glass ionomer showed the highest gaps. Table (1) and fig (1) these results were in accordance with Malhotra and Hegde (24) who concluded that there were statistically significant difference between biodentine and GI, where the least microleakage was seen in case of biodentine while the maximum microleakage was seen in GIC group.

The results of present study revealed that the presence of separate gaps that represents the space between the dentine and the filling material was assessed as studied by Torabinejad et al. ${ }^{(26)}$ and Fitzpatrick \& Steiman ${ }^{(27)}$, also in our study an image analysis program was used to calculate the whole area of gaps.

MTA Flow ${ }^{\mathrm{TM}}$ is calcium silicate based material with high $\mathrm{pH}$ of 12.5 . It has smaller particle sizes and shorter setting time of 15 minutes. Also has the ability to precipitate crystals at the junction of MTA and dentin that enhances marginal adaption. In our study the results showed that MTA Flow ${ }^{\mathrm{TM}}$ has the best marginal adaptation, this was in agreement with other studies that reported the better adaptation of MTA Flow ${ }^{(25,26)}$.

The results showed that there is no significant difference between MTA Flow and Harvard MTA this could be explained that both of the investigated 
materials had the same composition with calcium silicate as the main component Fig (2, 3, and 4). The results of our study were similar to the results reported by Torabinejad et al. ${ }^{(27)}$; and Gondim et al. (29) who concluded that MTA based materials have the best marginal adaptation compared to other tested materials.

The results of present study are in accordance with other studies that concluded that glass ionomer cement doesn't present good results when compared with other materials ${ }^{(30,31)}$.

Xavier et al. studied the marginal adaptation of MTA-Angelus, Super- EBA and Vitremer ${ }^{(32)}$. There were significant differences between the three tested materials. SEM results showed variable gaps between materials and the dentin interface, less gaps were detected in the MTA group, while the greatest gaps was found in the Vitremer group. Their results were in accordance with our results. Torabinejad et al. ${ }^{(27)}$ reported inferior marginal adaptation of Super-EBA and IRM as compared to MTA. They explained the absence of gaps in MTA samples to the possibility of the material expansion after setting.

Our results was in agreement to the results obtained by Bernabe et al. ${ }^{(33)}$ who compared the effect of different root end filling materials; MTA, Super-EBA, glass ionomer, IRM, and amalgam. They concluded that MTA was the material that had the best results, while IRM had the worst results and the other materials had the same results.

\section{CONCLUSION}

Based on the results of this in vitro study, SEM images showed presence of gaps in the root-end filling materials in the three groups. MTA flow has the best marginal adaptation followed by Harvard MTA while the Glass Ionomer cement showed the least marginal adaptation.

\section{ACKNOWLEDGEMENT}

The authors would like to express great appreciation to Dr Salah Ahmed Okasha, Lecturer of Plant Breeding and Biostatistic, Department of Agronomy, Suez Canal University (SCU), for the statistical analysis.

\section{Conflict of interest}

The authors deny any conflicts of interest to the present study.

\section{REFERENCES}

1. Estrela C, Estrada-Bernabé PF, de Almeida-Decurcio Dl,Almeida-Silva J, Rodrigues-Araújo-Estrela C, Poli-Figueiredo JA. Microbial leakage of MTA, Portland cement, Sealapex and zinc oxide-eugenol as root-end filling materials. Med Oral Patol Oral Cir Bucal. 2011;16(3):e418-24.

2. Gutmann JL, Harrison JW (1991) Surgical Endodontics, 1st edn,. Boston, MA, USA: Blackwell Scientifc Publications

3. Kim S (1997) Principles of endodontic microsurgery. Dental Clinics of North America 41, 481-97.

4. Kakehashi S, Stanley HR, Fitzgerald RJ (1965) The ejects of surgical exposure of dental pulps in germ-free and conventional rats. Oral Surgery 20,340^9.

5. Stabholz A, Shani J, Friedman S, Abed J. Marginal adaptation of retrograde fillings and its correlation with sealability. J Endod 1985;11:218-223.

6. Johnson BR. Considerations in the selection of a root-end filling material. Oral Surg Oral Med Oral Pathol Oral Radiol Endod. 1999; 87(4):398-404.

7. Nair PNR, Sjo«gren U, Krey G, Kahnberg K-E, Sundqvist $\mathrm{G}$ (1990) Intraradicular bacteria and fungi in root- $\phi$ lled, asymptomatic human teethwith therapy-resistant periapical lesions: a long term light and electron microscopic followup study. Journal of Endodontics16,580^8.

8. Rosales JI, Vallecillo M, Osorio R, Bravo M, Toledano $\mathrm{M}$. An in vitro comparison of micro-leakage in three glass ionomer cements used as retrograde filling materials. Int Dent J. 1996; 46(1):15-21.

9. Barkhordar RA, Pelzner RB, Stark MM. Use of glass ionomers as retrofilling materials. Oral Surg Oral Med Oral Pathol. 1989; 67(6):734-9. 
10. Chong BS, Pitt Ford TR, Watson TF. The adaptation and sealing ability of light-cured glass ionomer retrograde root fillings. Int Endod J. 1991;24:223-32.

11. Sarkar NK, Caicedo R, Ritwik P, Moiseyeva R, Kawashima I (2005) Physicochemical basis of the biologic properties of mineral trioxide aggregate. Journal of Endodontics 31, 97- 100 .

12. Hinata G, Yoshiba K, Han L, Edanami N, Yoshiba N, Okiji $\mathrm{T}$ (2017) Bioactivity and biomineralization ability of calcium silicate-based pulp-capping materials after subcutaneous implantation. International Endodontic Journal 50, e40-51.

13. Torabinejad M, Parirokh M, Dummer PMH (2018) Mineral trioxide aggregate and other bioactive endodontic cements: an updated overview - part II: other clinical applications and complications. International Endodontic Journal 51, 284-317.

14. Torabinejad M 2014 Mineral Trioxide Aggregate: Properties and Clinical Applications (Iowa US: Willey).

15. Bueno CRE, Vasques AMV, Cury MTS, et al. (2018) Biocompatibility and biomineralization assessment of mineral trioxide aggregate flow. Clinical Oral Investigations 23, https://doi.org/10.1007/s00784-018-2423-0

16. Guimar aes BM, Vivan RR, Piazza B, Alcalde MP, Bramante CM, Duarte MAH (2017) Chemical-physical properties and apatite-forming ability of Mineral Trioxide Aggregate Flow. Journal of Endodontics 43, 1692-6.

17. Lee SJ, Monsef M, Torabinejad M. Sealing ability of a mineral trioxide aggregate for repair of lateral root perforations. J Endod. 1993;19(11):541-4.

18. Radeva E, Uzunov T, Kosturkov D. Microleakge associated with retrograde filling after root end resection (in vitro study). Journal of IMAB - Annual Proceeding (Scientific Papers) 2014;20:578-83.

19. Morgan LA, Marshall JG. A scanning electron microscopic study of in vivo ultrasonic root-end preparations. Journal of Endodontics (1999) 25,567^70.

20. Peters CI, Peters OA. Occlusal loading of EBA and MTA root- fillings in a computer-controlled masticator: a scanning electron microscopic study. Int Endod J. 2002;35(1):22-9.

21. Mangin C, Yesilsoy C, Nissan R, Stevens R. The comparative sealing ability of hidroxyapatite cement, mineral trioxide aggregate and super ethoxybenzoic acid as root-end filling materials. J Endod 2003;29:261-264.
22. Sarris S, Tahmassebi JF, Duggal MS, Cross IA. A clinical evaluation of mineral trioxide aggregate for root-end closure of non-vital immature permanent incisors in childrena pilot study. Dent Traumatol 2008;24:79e85.

23. Witherspoon DE, Small JC, Regan JD, Nunn M. Retrospective analysis of open apex teeth obturated with mineral trioxide aggregate. J Endod 2008;34:1171e6.

24. Oliveira HF, Gonçalves Alencar AH, José Figueiredo AP, Guedes OA, de Almeida Decurcio D, Estrela C. Marginal Adaptation Evaluation of Root-End Filling Materials Using Scanning Electron Microscopy. Iran Endod J. 2013;8(4):183-7.

25. Malhotra S, Hegde MN. Analysis of marginal seal of ProRoot MTA, MTA Angelus biodentine, and glass ionomer cement as root-end filling materials: An in vitro study. J Oral Res Rev 2015;7:44-9.

26. Savitri D, Suprastiwi E and Margono A. Applying glass ionomer cement to MTA flowTM and biodentineTM and its effects on the interface layer : Journal of Physics: 2017 (884), 012109

27. Torabinejad M, Smith PW, Kettering JD, Pitt Ford TR. Comparative investigation of marginal adaptation of mineral trioxide aggregate and other commonly used root-end filling materials. J Endod. 1995;21(6):295-9.

28. Fitzpatrick EL, Steiman R (1997) Scanning electronmicroscopic evaluation of $\notin$ nishing techniques on IRMand EBA retrofillings. Journal of Endodontics 23, 423^7.

29. Gondim E Jr, Zaia AA, Gomes BA, Feraz CR, Teixeira FB, Souza-Filho FJ. Investigation of the marginal adaptation of root-end filling materials in root-end cavities prepared with ultrasonic tips. Int Endod J 2003;36:491-499.

30. Siqueira JF, Rocas IN, Abad EC, Castro AJR, Gahyva SM, Favieri A. Ability of three root-end filling materials to prevent bacterial leakage. J Endod 2001;27:673-675.

31. Biggs JT, Benenati FW, Powell SE. Ten-year in vitro assessment of the surface status of three root-end filling materials. J Endod 1995;21:521-525.

32. Xavier CB, Weismann R, de Oliveira MG, Demarco FF, Pozza DH. Root-end filling materials: apical microleakage and marginal adaptation. J Endod. 2005;31(7):539-42.

33. Bernabe PF, Holland R, Morandi R, de Souza V, Nery MJ, Otoboni Filho JA, Dezan Junior E, Gomes-Filho JE. Comparative study of MTA and other materials in retrofilling of pulpless dogs' teeth. Braz Dent J. 2005;16(2):149-55. 